\title{
Afetler Sırasında Hasta ve Yaralılara Müdahalede Sığınak Görevi \\ Afetler Sırasında Hasta ve Yaralılara Müdahalede Sığınak Görevi
Yapan Yer Altı Hastanelerine Genel Bir Bakış Rabia DAĞDAŞ ${ }^{1}$
}

\section{Öz}

Dünya geliştikçe hayatımızı tehdit eden riskler de artmaktadır. Bu riskler birçok faktöre bağlı olarak doğal ve beşeri afetleri doğurmaktadır. Meydana gelen afetin türü fark etmeksizin bu olaylarda toplumun ihtiyaç duyduğu ilk hizmet sağlık hizmetidir. Sağlık hizmeti veren kurumların başında ise hastaneler gelmektedir. Hastaneler, yalnızca doğal afetlere karşı değil aynı zamanda savaş, çatışma ve terör sonucu kimyasal, biyolojik, radyoaktif ve nükleer maddelerin kasten veya kazaen yayılmasıyla oluşan insan ve çevre için zararlı olaylar gibi beşeri afetlere karşı da dirençli olmalıdır. Hastaneler bu tür durumlarda mümkün olduğu kadar dış ortamdan etkilenmeden kendini izole edebilmeli ve hasta-yaralılara herhangi bir aksaklık olmadan sağlık hizmeti verebilmelidirler. Bu araştırmada, ülkemizde mevcut olmayan, ancak savaşların meydana geldiği bölgelerde görev yapmış ve yapmakta olan yer altı hastaneleri ile bunların coğrafi konumları ve fiziksel özellikleri hakkındaki bilgiler derlenmeye çalışılmıştır.

Anahtar Kelimeler: Afetlerde sağlık hizmeti, Hastanelerin korunması, Savaşlarda hastaneler, Afet risklerinin azaltılması

\section{A General Overview of Underground Hospitals Acting as Shelter in Intervention to Patients and Wounded During Disasters}

\begin{abstract}
As the world develops, the risks that threaten our lives increase. These risks cause natural and human disasters depending on many factors. Regardless of the type of disaster occurring, the first service that the community needs is the health service. Hospitals are most important institutions that provide health services. Hospitals should be resistant to human and environmental hazards caused by war, conflict, and terror that are intentionally or accidently spread by chemical, biological, radioactive and nuclear substances as well as natural disasters. In such cases, hospitals should be able to isolate themselves as much as possible without being affected by the external environment and provide healthcare services to the sick-injured without any problems. In this study, it was tried to compile information about underground hospitals that are not present in our country but have been working in the regions where wars occurred and their geographical locations and physical properties.
\end{abstract}

Keywords : Health cervice in disasters, Protection of hospitals, Hospitals in war, Disaster risk reduction

\section{GíRiş}

Dünya geliştikçe hayatımızı tehdit eden riskler de artmakta ve bu riskler birçok faktöre bağlı olarak doğal ve beşeri afetleri doğurmaktadır. Meydana gelen afetler insan hayatı ve sağlığı başta olmak üzere pek çok kayba neden olmaktadır. Bu kayıpların sebeplerinden bir tanesi ise sağlık hizmetine erişimin olmaması veya sınırlı olmasıdır.

\footnotetext{
${ }^{1}$ Afet Eğitimi ve Yönetimi Yüksek Lisans Programı Öğrencisi, Çanakkale Onsekiz Mart Üniversitesi, Çanakkale

*ilgili yazar / Corresponding author: rabia.dagdas@gmail.com

Gönderim Tarihi / Received Date: 11.08.2019

Kabul Tarihi / Accepted Date: 29.05.2020
}

Bu makaleye atıf yapmak için- To cite this article Dağdaş, R. (2020). Afetler Sırasında Hasta ve Yaralılara Müdahalede Sığınak Görevi Yapan Yer Altı Hastanelerine Genel Bir Bakış. Resilience, 
Sağlık hizmeti veren tesislerin başında gelen hastaneler, yalnızca doğal afetlere karşı değil aynı zamanda savaş, çatışma ve terör sonucu kimyasal, biyolojik, radyoaktif ve nükleer maddelerin (KBRN) kasten veya kazaen yayılmasıyla oluşan insan ve çevre için zararlı olaylar gibi beşeri afetlere karşı da dirençli olmalıdır. Hastaneler bu tür durumlarda mümkün olduğu kadar dış ortamdan etkilenmeden kendini izole edebilmeli ve hasta-yaralılara herhangi bir aksaklık olmadan sağlık hizmeti verebilmelidirler. Bu ihtiyaçtan yola çıkılarak tasarlanmış olan yer altı hastanelerinin olduğu bilinmektedir.

Ülkemizde yer altı hastanesi henüz mevcut değildir. Bu çalışma, savaş, çatışma, terör ve KBRN olaylarının yaşandığı ve yaşanma ihtimallerinin olduğu yerlerde, geçmişte kullanılmış, halen kullanılmakta olan ve kullanılması planlanan yer altı hastaneleri hakkında genel bir bakış açısı sunmaktadır. Çalışmada veri toplama yöntemi olarak belgesel kaynak tarama teknikleri kullanılmıştır. İnternet kaynakları üzerinden ulaşılan haber, dergi ve makalelerden elde edilen veriler derlenmeye çalışılmıştır.

\section{BİRINCI DÜNYA SAVAŞINDA YER ALTI HASTANELERI}

1914-1918 yılları arasında kullanılan Carriere Suzanne bölgesindeki yapı, Fransa'nın kuzeyindeki Montigny taş ocağı bölgesinde bulunmaktadır (Machemontoise, 2019). Taş ocağının, askerin dinlenmesi ve tedavisi için kullanılması amacıyla küçük bir hastaneye çevrildiği anlaşılmaktır. 2016 yılında March Askat tarafından keşfedilen ve Şekil 1'de görüldüğü gibi fotoğraflanan yapının yeri, askeri günlükler okunduktan sonra tespit edilmiştir (Charlton, 2016).

Carriere Wellington, Fransa'nın kuzeyinde bulunan ve askeri operasyon için Yeni Zelandalı işçiler tarafından inşa edilmiş bir tünel ağıdır (Şekil 2). 25.000 kişiyi barındırabilecek kapasitede olan yapı, askerlerin sağlık intiyaçlarını karşılayabilecekleri bir hastaneyi de bünyesinde barındırmaktadır (Derby, 2014).

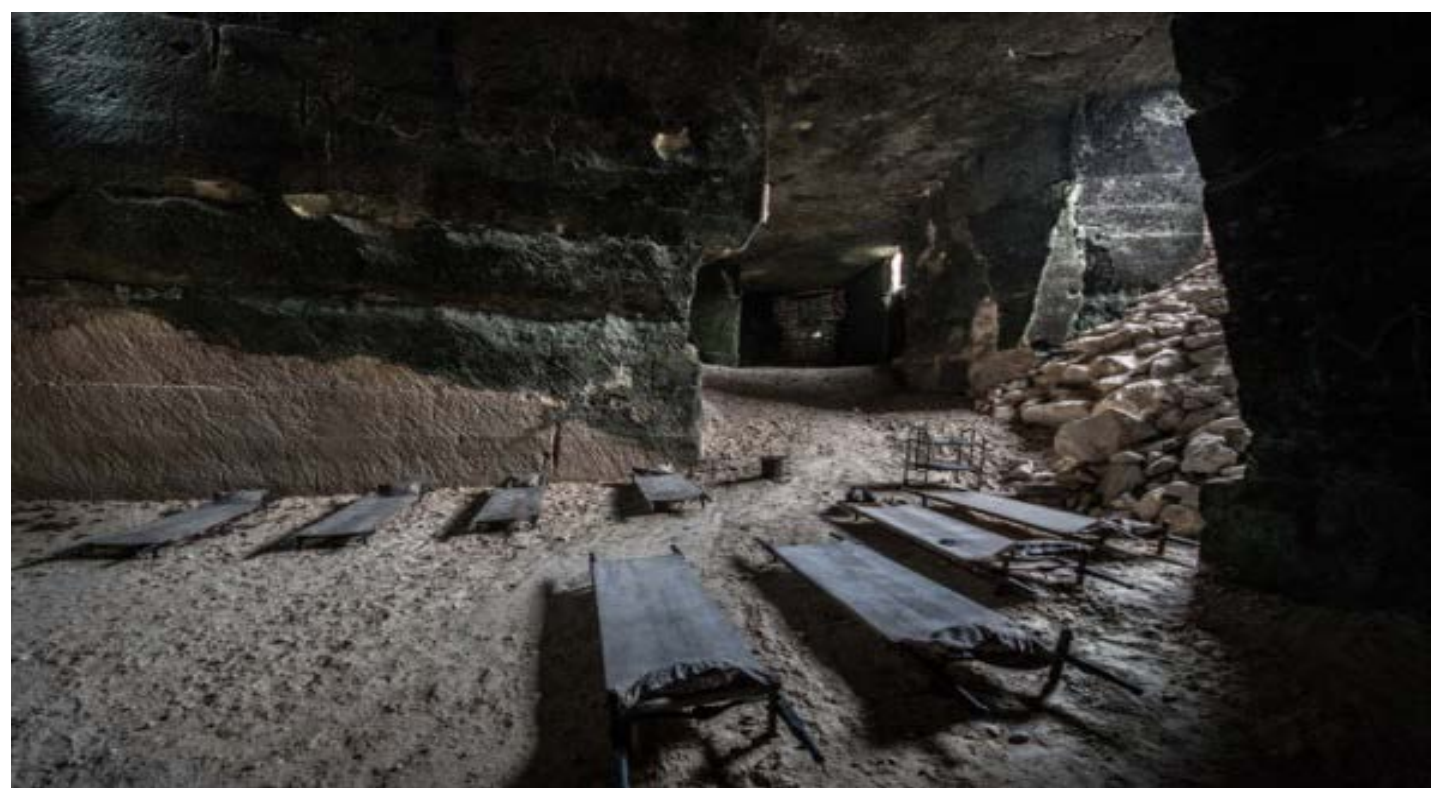

Şekil 1. Montigny taş ocağı (Les Carrıères De Montıgny, (2019) 


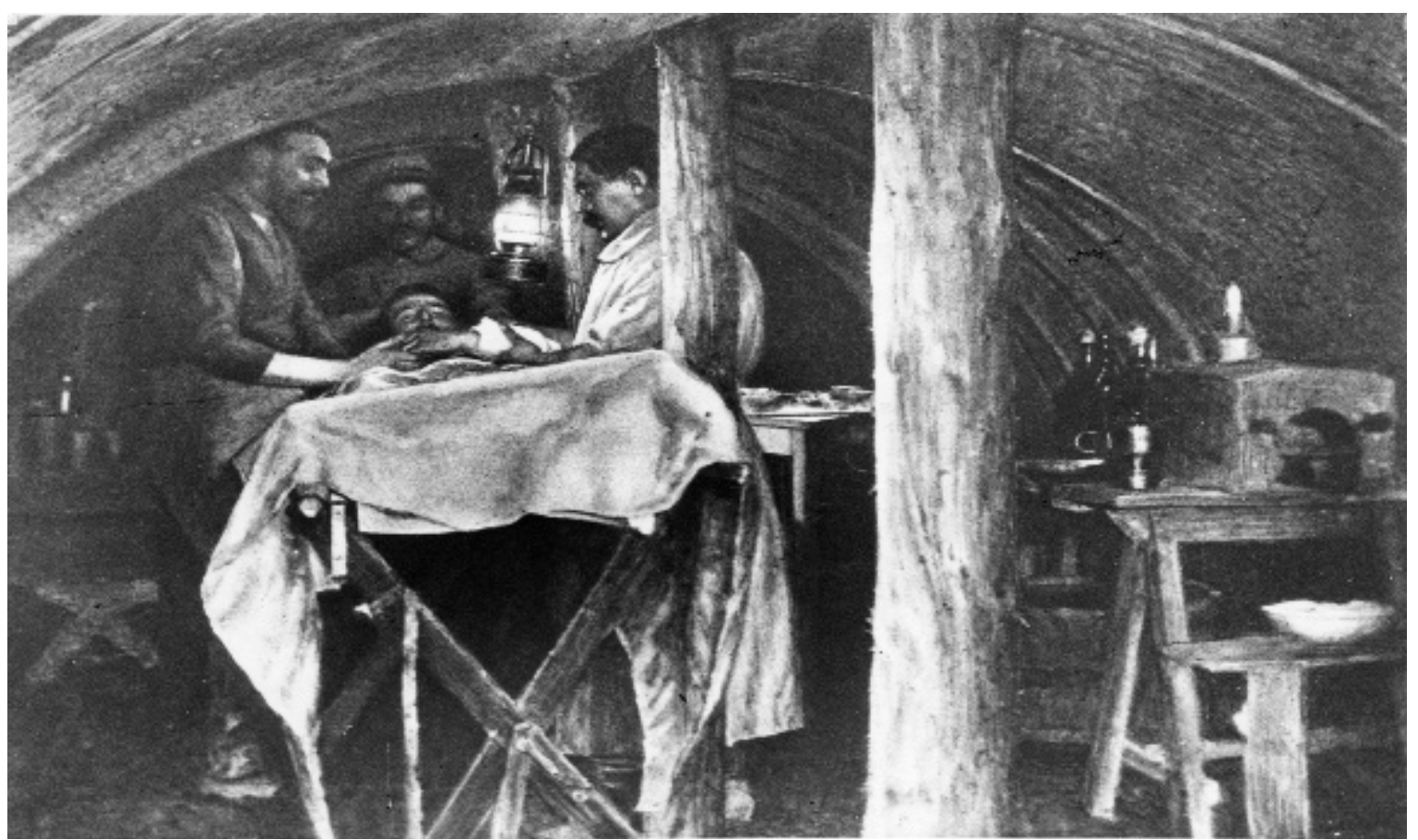

Şekil 2. Carriere Wellington'daki yer altı hastanesi (Speiser, t.y.)

\section{3. ÍKINCI DÜNYA SAVAŞINDA YER ALTI HASTANELERI}

Alman Yer Altı Hastanesi, İngiltere'nin Manş Adaları'nda 6.950 metrekarelik alana inşa edilmiştir. Hastane planında nöbetçi odası, hasta odaları, ameliyathane, mutfak, acil kaçış koridorları, su deposu, asansör, morg, sinema salonu, depo ve tuvaletler yer almaktadır (German Underground Hospital, t.y.). Yapımı üç buçuk yıl süren yapı yalnızca dokuz ay kullanılabilmiştir. Yer altı yapısında ameliyathaneler ve hasta odaları mevcuttur ancak hiçbir zaman inşa amacıyla kullanılamamış, belli bir dönem mühimmat deposu olarak kullanılmıştır. 9 Mayıs 1945'te İngiltere'nin Manş Adaları'na tekrar hakim olmasıyla keşfedilmiş ve hastane içindeki tıbbi ekipmanların taşınmasının ardından yapı müzeye çevrilmiştir (Fairclough, 1993: İnsight Guides, 2017).

Mtarfa Askeri Hastanesi, Malta Adası'nda bulunmaktadır. Hastane İkinci Dünya Savaşı sırasında diğer hastanelerin kapatılması ve kendisinin de bölgede hizmet veren tek hastane olması sebebiyle zor bir dönem yaşamıştır. Artan sağlık hizmeti intiyacından dolayı hastanenin altına 1.200 yatağı barındırabilecek bir yer altı hastanesi kazılmıştır (Ventura, 2001). Acil bir ameliyathaneyi de barındıran üç katlı yapı ilk kez 11 Kasım 2018'de halk ziyaretine açılmıştır (Valletta, 2018).

Mount Isa Yer Altı Hastanesi Avustralya'nın Queensland şehrinin kuzeybatısında yer almaktadır. İkinci Dünya Savaşı'nda Avustralya'nın kuzey topraklarında yer alan Darwin şehri 19 Şubat 1942'de başlayan Japon hava saldırısına maruz kalmış ve bu saldırıda Darwin Hastanesi de bombalanmıştır. Bu durumda endişelenen tıbbi müfettiş Dr. Ryan tedbir amaçlı olarak, Mount Isa Hastanesinin arkasında yer alan tepelere hastane sığınağı kazılmasını önermiştir. Maden bölgesinde yer alan hastane, maden işçilerinin desteğiyle kazılarak 4 Temmuz 1942'de tamamlanmıştır. Hastane sığınağı "E" şeklinde planlanmış ve içerisinde hasta odaları, ameliyathane, doğumhane, kadın ve çocuk hastalıkları servisi bulunmaktadır. Hastane tamamlandıktan sonra haftada bir kez, hareket kabiliyeti kısıtı olan hastaların da dahil edildiği hava saldırısı tatbikatı yapılmıştır. Savaş boyunca hastaneye veya hastanenin bulunduğu bölgeye saldırı yapılmamıştır. Hastane zamanla depo olarak kullanılmaya başlanmış ardından terkedilmiştir. Hastanenin iç bölümlerinden fotoğraflara ulaşılmış (Şekil 
3) ancak dış yapısıyla ilgili görsel kaynağa ulaşılamamıştır (Bell, 1997; Kirkman, 2011). 1997 yılında restore edilen yapı müzeye çevrilmiş ve 2001'de ziyarete açılmıştır (Katherine Times, 2014).

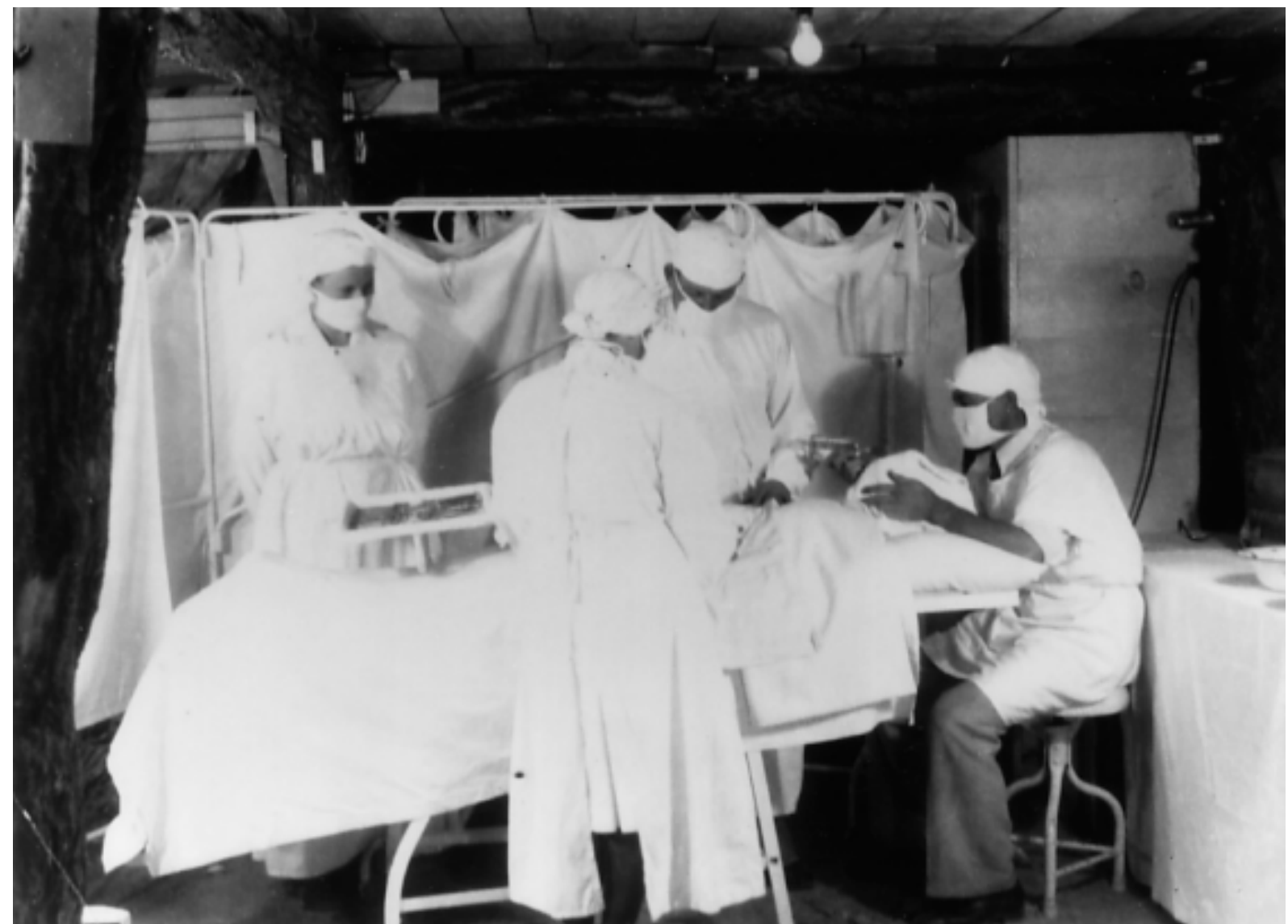

Şekil 3. Mount Isa Yer Altı Hastanesi (Bell, 1997).

\section{YUGOSLAVYA'NIN DAĞILMASINDA YER ALTI HASTANELERI}

Vukovar Hastanesi, Hırvatistan ve Sırbistan'ın kuzey sınırındaki Vukovar şehrinde yer almaktadır. Hastane, savaştan önce 120 doktor ve 400 yatağı ile 800.000 'den fazla insana sağlık hizmeti veren birinci ve ikinci basamak sağlık merkezi durumundayken 1991 yılındaki gergin dönemde üç ay boyunca kuşatma altında kalmış, bombalamalar ve saldırılar sonucu hastane ağır hasar almıştır. Saldırı altında olduğu dönemde günde 80 hasta kabul edebilmiştir. Bombalamalar sonucu hastanenin üst katlarında meydana gelen hasarlar sebebiyle, katlardaki servisler yer altı sığınaklarına taşınmak zorunda kalmış, yoğun bakım ünitesi ise nükleer saldırıdan etkilenmeyen bir bölüme taşınmıştır (Horton, 1999). Krizin yaşandığı dönemde 1.700 'den fazla yaralı bu hastanede ameliyat edilmiştir. Bünyesinde üç ameliyathane, yoğun bakım ünitesi, doğum salonu ve tüm hastaların yerleştirildiği odalarla birlikte mutfak ve çamaşır odasını barındıran hastane sığınağı, küçük bir yer altı şehrine benzetilmiştir (Habek, Dujaković, Habek ve Jurković, 2016). Mostar'da da iki hastanenin altı kez bombalanmasının ardından tıpkı Vukovar'da olduğu gibi hastaların yer altına taşındığından bahsedilmiş ancak bu iki hastane hakkında detaylı bilgiye ulaşılamamıştır (Hortan, 1999).

\section{GÜNÜMÜZDE YER ALTI HASTANELERI}

Batı Celile Sağlık Merkezi, İsrail'in kuzeyindeki Celile bölgesinin 700 yatağa sahip en büyük devlet hastanesidir (Galilee Medical Center, 2019). Hastaneye yer altı sığınağının eklenmesi fikri 80'li yıllara kadar dayanmaktadır. O dönemlerde Nahariya'ya yapılan roketli saldırılarda 
bir roketin Batı Celile Hastanesi'nin kadın doğum servisine isabet ettiği ve üç personelin yaralandığı olay sonrasında, dönemin hastane müdürü olan Prof. Sasha, hastaneye yer altı sığınağı yapılması önerisinde bulunmuş, ancak o zamanki yetkililerin çoğu bu fikri para israfı olarak görüp fikri reddetmiş ancak saldııların devam etmesiyle sığınak fikri uygulamaya koyulmuştur (Eisenman, 2006). İsrail, ilk yer altı hastanesini 2006 yılında Lübnan'la yaptığı İkinci İsrail-Lübnan Savaşı'nda kullanmıştır. Bu yer altı hastanesinde 450 yatak mevcut olup kimyasal ve biyolojik saldırılara karşı dayanıklı olarak inşa edilmiştir. Krizin yaşandığı dönemde hastaneye başvuran hastalar, travma ve travma dışı olarak ikiye ayrılarak yer altı tesislerine yönlendirilmiştir. Travmalı hastaların karşılandığı acil serviste yaşanacak yoğunluğu azaltmak için pek çok önlem alınmış, acil servis ise, düzeni ve işleyişi yeniden planlanmıştır. Travmalı olmayan hastaların karşılandığı acil serviste, günlük tıbbi aktiviteler devam etmiş ve bir toplum sağlığı merkezi gibi işletilerek bir sığınak görevi görmüştür. Bu dönemde hastaneye başvuranların triaj grupları kaydedilmiştir( Şekil 4). Hastaların yarısından fazlasında Akut Stres Bozukluğu tespit edilmiştir. Ayrıca güvenlik endişesiyle hastaneye getirilen çocuklar, hastanenin kreş ve anaokulunda misafir edilmişlerdir (Eisenman, 2006: Lino, Eisenman, Schuster, Giloni, Bharoum, Daniel ve Dallas, 2015).

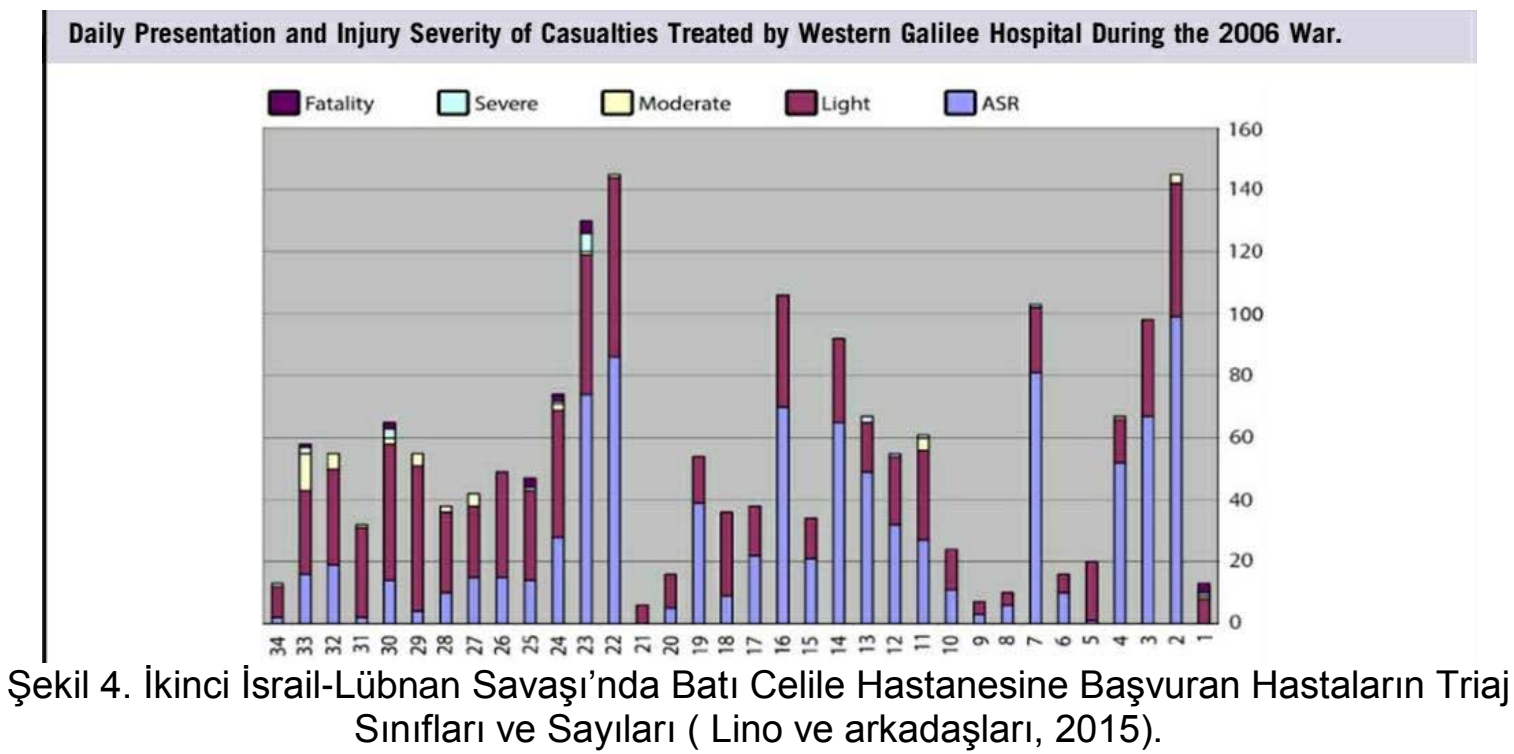

Rambam Sağlık Kampüsü, İsrail'in kuzeyindeki Hayfa şehrinde bulunmaktadır. Hastane 1.000 yataklı bir eğitim hastanesidir. Hastane 2006'daki İkinci İsrail-Lübnan Savaşı sırasında zorluklar yaşamıştır. Saldırılara karşı bir takım önlem almış olsa da savaş sırasında fiziksel imkansızlık sebebiyle durumu hafif olan hastalarının bir kısmını diğer hastanelere sevk etmek durumunda kalmıştır. Bu zor şartlar altında bile hastane rutin zamanlardaki gibi işlemeye devam etmeye çalışmış, savaş dışı 7.000 acil servis, 26.000 poliklinik, 941 elektif cerrahi, 4.700 yatışı yapılmış hasta tedavi edilmiş ve 200 doğum gerçekleştirilmiştir (Bar-El, Michaelson, Hyames, Skorecki, Shimon, Reisner ve Beyar, 2009). Yaşanan tecrübeler üzerine hastane yapısı gözden geçirilmiş ve hastane güçlendirilmiştir. Güçlendirilen yapıda, benzer durumlarda kullanılmak üzere yer altında üç katlı olarak inşa edilmiş bir bölümü bulunmaktadır. 2014 Nisan ayında kullanıma açılan bu kısım çift fonksiyonlu olarak kullanılmaktadır. Rutin zamanlarda 1.500 araçlık bir yer altı otoparkı olarak kullanılan alan, ihtiyaç halinde 72 saat içinde 2.000 yataklı bir hastaneye dönüşebilmektedir (Rambam Health Care Campus, 2019). Bu bölümde, 1493 standart hasta yatağı, 146 doğum yatağı, 120 inkübatör/bebek yatağı, 97 yoğun bakım yatağı, 95 diyaliz standı ve 49 pediatrik yatak bulunmaktadır (Bıçakçı ve Ulutaş, 2019). Ayrıca hastanenin en alt katı Ebola hastaları ve şüphelileri için izole edilmiş ve kullanıma hazır hale getirilmiştir (Rambam Health Care Campus, 2019). 
Suriye'de Mart 2011'de başlayan iç savaşta, sınırlı da olsa yer altı hastanelerinin aktif şekilde kullanıldığını öğrendiğimiz kaynaklar mevcuttur. Yer altı hastane modeline başvurma nedeni diğer örneklerle paralellik göstermektedir. İç savaşın başladığı tarihten Şubat 2017'ye kadar 814, 2018'de ise 102 olmak üzere saldırılar sonucu toplam 916 sağlık çalışanı hayatını kaybetmiştir (Fallon ve Kieval, 2017: OCHA, 2019). Şubat 2016'da Sınır Tanımayan Doktorlar (Médecins Sans Frontières MSF) Suriye'deki hastane koordinatlarını Suriye ve Rus yetkililere vermeyi durdurmuştur (Francis, Sidahmed, Huffaker, Hylton ve Agrawal, 2016). Sağlık merkezlerinin ve sağlık çalışanlarının hedef alınması endişeleri artırmıştır. Suriye'de faaliyet gösteren on üç farklı sivil toplum kuruluşunun bir araya gelerek hazırladığı "Yeraltında Hayat Kurtarmak" isimli rapor Suriye'deki yer altı hastaneleri ile ilgili bilgi vermektedir. Yer altı hastaneleri, bodrum katı hastaneler, mağara hastaneleri ve yer altı hastaneleri olmak üzere üç gruba ayrılmış, inşası yer seçimi ve maliyeti hakkında detaylı bilgilere yer verilmiş ve her biri örneklendirilmiştir. Bodrum katı hastanesine Halep'in doğusunda yer alan Syrian American Medical Society (SAMS)'ın Al Sakhour (M10) Hastanesi örnek verilmiş, bodrum katı hastanelerinin diğerlerine göre daha az güvenli olduğu ancak SAMS AI Sakhour Hastanesi'nde hiç can kaybının yaşanmadığı belirtilmiştir. Mağara hastanelerine ise Central Cave Hastanesi örnek verilmiş ancak yapının yeri ve ismi güvenlik gerekçesiyle paylaşılmamış, yalnızca Hama'nın kırsalında yer aldığı, cerrahi ve ortopedi ameliyatlarına ev sahipliği yaptığı ve ayda 1.300 vakayı tedavi ettiği belirtilmiştir. Söz konusu hastanenin bombardımana ve hava saldırısına maruz kalmasının ardından hastanenin tahrip olduğu ve yer altına taşındığı belirtilmiştir. Bu hastanelere ek olarak Avicenna National Hastanesi inşa halinde olup tamamlandığında İdlib'in en büyük hastanesi olacağı ifade edilmiştir. Hastanenin iki seviyeden oluştuğu, birinci seviyesinde bir ameliyathane, bir acil ameliyathanesi, cerrahi ve cerrahi olmayan yoğun bakım ünitesi, bir acil servis barındıracağı söylenmiştir. İkinci seviyesinde ise özel anne ve çocuk sağlığı hizmeti sağlayacak olan Avicenna Kadın ve Çocuk Hastanesi ile birlikte iç hastalıkları bölümüne ve 14 ameliyathaneye ev sahipliği yapacağı belirtilmiştir. (Fallon ve Kieval, 2017). Suriye Hastaneleri Sürveyans Çalışması'na göre Suriye'de 21 yer altı hastanesi, 71 bodrum katı hastane ve 4 mağara hastanesi bulunmaktadır (Union of Medical Care and Relief Organizations, 2017).

İtalya'daki Gemelli Yer Altı Kitlesel Olay Hastanesi (Gemelli Underground Major Incident Hospital- GUMIH)'nin, Roma'daki Policinio A. Gemelli (PAG) Hastanesi'nin acil servisine entegre bir yer altı tesisi olarak inşa edilmesi planlanmaktadır. PAG, Roma'nın en büyük hastanesi konumunda olup, 90'ı yoğun bakım ünitesinde olmak üzere 1300'den fazla yatağa ve 30 ameliyathaneye sahip birinci derece travma merkezidir. Yapım aşamasında olan GUMIH'in, PAG acil servis kapasitesinin dolması halinde hizmet vermesi beklenmektedir. Burada ayrıca; kırmızı ve sarı kodlu hastalar için 112 yatak ve bir resüsitasyon odası, bulaşıcı hastalık şüphesi taşıyan hastalar için dört tedavi odası, kitlesel olaylar için bir VIP odası, iki ameliyathane ve bir de bilgisayarlı tomografi cihazının olduğu bir ünite bulundurulacaktır. Proje 2013'te başlamış ve tasarım planları tamamlanmıştır, GUMıH'in inşası için fon çalışmaları devam etmektedir (Haverkort, Jong, Foco, Gui, Barhoum, Hyams, Bahouth, Halberthal ve Leenen, 2016).

\section{SONUÇ}

Yer altı hastaneleri, farklı yerlerde farklı zamanlarda benzer intiyaçları giderebilmek için inşa edilmiş ve kullanılmışlardır. Genel olarak yer altı hastane modeli, sığınak yapısının hastanelere uyarlanmasıyla ya da sağlık intiyacının karşılanması için yer altı yapılarına sığınılmasıyla ortaya çıkmış olduğu söylenebilir. Bu sebeple yer altı hastanelerine, sağlık merkezlerine uyarlanmış gelişmiş sığınaklardır denilebilir. 
Sağlık intiyacının karşılanması için öncelikli olarak sağlık çalışanlarının can güvenliği sağlanmalıdır. Ancak çalışmadaki örneklerde de görüldüğü üzere hastaneler savaş sırasında doğrudan saldırı hedefi olabilmektedir (Fallon ve Kieval, 2017; Francis, Sidahmed, Huffaker, Hylton ve Agrawal, 2016). Bu soruna çözüm olarak kullanılan yer altı hastanelerinde hiç can kaybının yaşanmamış olması sebebiyle bu yapıların daha güvenli olduğu söylenebilir (Fallon ve Kieval, 2017).

Afet durumlarında sağlık hizmetlerinin devamlılığı açısından gelişmiş yer altı sığınakları fikrini farklı bir açıdan yorumlayan Rauof ve Raof (2017), güvenli şehir planlamasını konu aldıkları bir makalede, yer altı sığınak ve tünellerinin, okul ve hastane gibi çeşitli kamu binalarında bulunmasının özellikle insan kaynaklı afetlerde hayat kurtarabileceğinden bahsetmişlerdir. İkinci Dünya Savaşı sırasında Polonya'da yer altına kurulan tıp fakültesi, Polonyalı öğrencilerin, bir süre eğitimlerine devam etmelerini sağlamıştır (Roland, 1989).

$\mathrm{Bu}$ örneklere de dayanarak, savaş, çatışma, KBRN olayları gibi insan kaynaklı afet durumlarında, yer altı hastanelerinin gerek sağlık personelinin can güvenliği gerekse sağlık hizmetlerinin sürekliliği açısından, özellikle ülkemizin de yakın temasta olduğu Ortadoğu gibi riskli bölgelerde etkili bir şekilde kullanılabileceği ve hatta sağlık dışında farklı amaçlar için tasarlanacak yer altı yapıları ile normal hayatın devam ettirilmesine yardımcı olacağı söylenebilir.

Ancak daha nesnel yargılara ulaşabilmek adına, çeşitli disiplinlerdeki araştırmacıların, yer altı hastaneleri ve sığınaklar ile ilgili farklı bakış açısı kazandırabilen araştırma sayılarının artırılması gerektiği düşünülmektedir.

\section{KAYNAKLAR}

About The German Underground Hospıtal. (2019). Erişim adresi: http://www.germanundergroundhospital.co.uk/about/ (24.05.2019)

Bar-El, Y., Michaelson, M., Hyames, G., Skorecki,K., Reisner, S.A., and Beyar, R. An Academic Medical Center Under Prolonged Rocket Attack-Organizational, Medical, and Financial Considerations. Academic Medicine. 2009; 84, 1203-1210. doi: https://doi:10.1097/ACM.0b013e3181b18bd6 (13.06.2019)

Bell, P. (1997). Mount Isa Underground Hospital Conservation Strategy report to Underground Hospital Steering Committee. Adelaide SA: Historical Research. Erişim adresi: https://catalogue.nla.gov.au/Record/232265 (27.05.2019)

Bıçakçı, N., Ulutaş, M. (2019). Gizli ve Güvenli; Yer Altı Hastaneleri. Namık Kemal Tıp Dergisi. 2009; 7(3): 291-298. Erişim Adresi: https://dergipark.org.tr/en/download/articlefile/891558 (24.01.2020)

Charlton, C. (2016, 4 Mart). Inside the secret underground First World War hospital which once saved the lives of wounded Allied and German soldiers in France but has now been reclaimed by nature [Haber yazısı]. Erişim adresi: https://www.dailymail.co.uk/news/article3476546/Inside-secret-underground-World-War-hospital-saved-lives-wounded-Allied-

German-soldiers-France-reclaimed-nature.html (24.05.2019)

Derby, M. (2014, Haziran). Underground Soldiers. School Journal, 4, s. 31-37. Erişim adresi: http://instructionalseries.tki.org.nz/content/download/27600/292333/file/L4\%20June\%202014 \%20U nderground\%20Soldiers.pdf (24.05.2019)

Eisenman, A. (2006). Emergency Care Under Fire and Underground: A Personal Narrative. Israel Journal of Emergency Medicine, 6, s.5-9. Erişim adresi: http://fliphtml5.com/xcxs/eask/basic (13.06.2019). 
Fairclough, A. (1993). The German Underground Hospital in Jersey, Museum International, 177, s. 42-43. Erişim adresi: https://unesdoc.unesco.org/ark:/48223/pf0000094291 (11.06.2019)

Fallon, K. Kieval, N. (2017). Saving Lives Underground the Case for Underground Hospitals in Syria. The Syria Campaign (Rapor No: 1.0). Erişim adresi: https://savinglivesunderground.thesyriacampaign.org/ (10.06.2019)

Francis, E., Sidahmed, M., Najmabadi, S., Huffaker, C., Hylton, A., Agrawal, N. (2106). The Secret History of Syrian Rebel Medicine. Erişim adresi: http://medicineunderground.org/

Galilee Medical Center. (2019). About The Medical Center. Erişim adresi: http://www.gmc.org.il/?CategorylD=843 (13.06.2019)

Habek, D., Dujaković T., Habek, J.C., Jurković I. (2016). Twenty-Three-Year Long-Term Health Outcome After The War In Vukovar. Acta Clinica Croatica, Cilt 55, s. 58-62. https://doi:10.20471/acc.2016.55.01.9

Horton, R. (1999, Haziran). Croatia and Bosnia: the imprints of war-I. Consequences. The Lancet, 353, s. 2139-44. doi: https://doi:0.1016/S0140-6736(99)05242-3

Hoverkort, J.J.M., Jong, M. B., Foco, M., Gui, D., Barhoum, M., Hyams, G., Bahouth, H., Halberthal, M., Leenen, L. P.H. (2016). Dedicated Mass-Casualty Incident Hospitals: An Overview, Injury, 48, s.322-326. doi: https://doi.org/10.1016/j.injury.2016.11.025 (11.06.2019)

İnsight Guides. (2017, Mayıs). Great Breaks Guernsey. Erişim adresi: https://books.google.com.tr/books?id=3ytHDwAAQBAJ\&amp;pg=PT104\&amp;dq\#v=onepag e\&amp;q\&amp; $f(01.06 .2019)$

Kirkman, N., S. (2011). Mount Isa Mines social infrastructure programs 1924-1963. (Yayımlanmamış Doktora Tezi). James Cook University, Australia. Erişim adresi: https://researchonline.jcu.edu.au/39437/1/39437-kirkman-2011-thesis.pdf

Les Carrıères De Montıgny. (2019). Erişim adresi: https://www.lescarrieresdemontigny.fr/lescarrieres-de-montigny.php (24.05.2019)

Lino, B., Eisenman, A., Schuster, R., Giloni, C., Bharoum, M., Daniel, M., \&amp; Dallas, C. (2015). The Second Lebanon War Experience at Western Galilee Hospital. Disaster Medicine and Public Health Preparedness, 10, s. 152-156. doi: https://doi.org/10.1017/dmp.2015.80 (14.06.2019)

Queensland gem a state of mine. (2014,10 Eylül ).[Gazete küpürü, Katherine Times].s.39 Erişim adresi: https://www.territorystories.nt.gov.au/jspui/bitstream/10070/265484/40/X10KTT_039p.pdf (27.05.2019).

Rauof, T. A., Raof, B., Y. (2017, 17-18 Mayıs ). Urban Safe Heaven: Planning and Design. International Research Conference on Civil, Architectural and Environmental Engineering. doi: https://doi.org/10.15242/DIRPUB.DIR0517406 (01.06.2019)

Roland, C. G. (1989). An Underground Medical Scool in Warsaw Ghetto, 1941-2. Medical History. 1989, 33: 399-419. Erişim: https://www.ncbi.nlm.nih.gov/pmc/articles/PMC1035933/pdf/medhist00057-0005.pdf

Speıser, W. Şekil 2. (Tarih yok). [1.Dünya Savaşı, Yer Altı Ameliyathanesinden Bir Fotoğraf]. ICRC Arşivleri (Referans: VP-HIST-02996-08) Erişim adresi: https://avarchives.icrc.org/Picture/10792 (15.07.2019)

Union of Medical Care and Relief Organizations (UOSSM). (2017, Mart). Syrian Hospitals Survellance Study. 
https://reliefweb.int/sites/reliefweb.int/files/resources/UOSSM\%20Hospital\%20Study\%20Mar ch\%202017.pdf

United Nations Office for the Coordination of Humanitarian Affair. (2019). Syrian Arab Republic Humanitarian Needs Overview. Erişim adresi: https://reliefweb.int/sites/reliefweb.int/files/resources/2019_Syr_HNO_Full.pdf

Valletta. (2018). Military Mtarfa 2018. Erişim adresi: https://valletta2018.org/events/militarymtarfa-2018/ (09.06.2019)

Ventura, C. S. (2001). Military and Naval Hospitals in Malta in the Last Two Centuries. Historia Hospitalium Zeıtschrift Der Deutschen Gesellschaft For Krankenhausgeschıchte. Erişim adresi: https://www.um.edu.mt/library/oar/bitstream/handle/123456789/23704/CSVMilitary\%20and\% 20Naval\%20Hospitals\%20in\%20Malta\%20in\%20the\%20last\%20two\%20Centuries.PDF?seq uence=1\&amp;isAllowed=y $(09.06 .2019)$ 